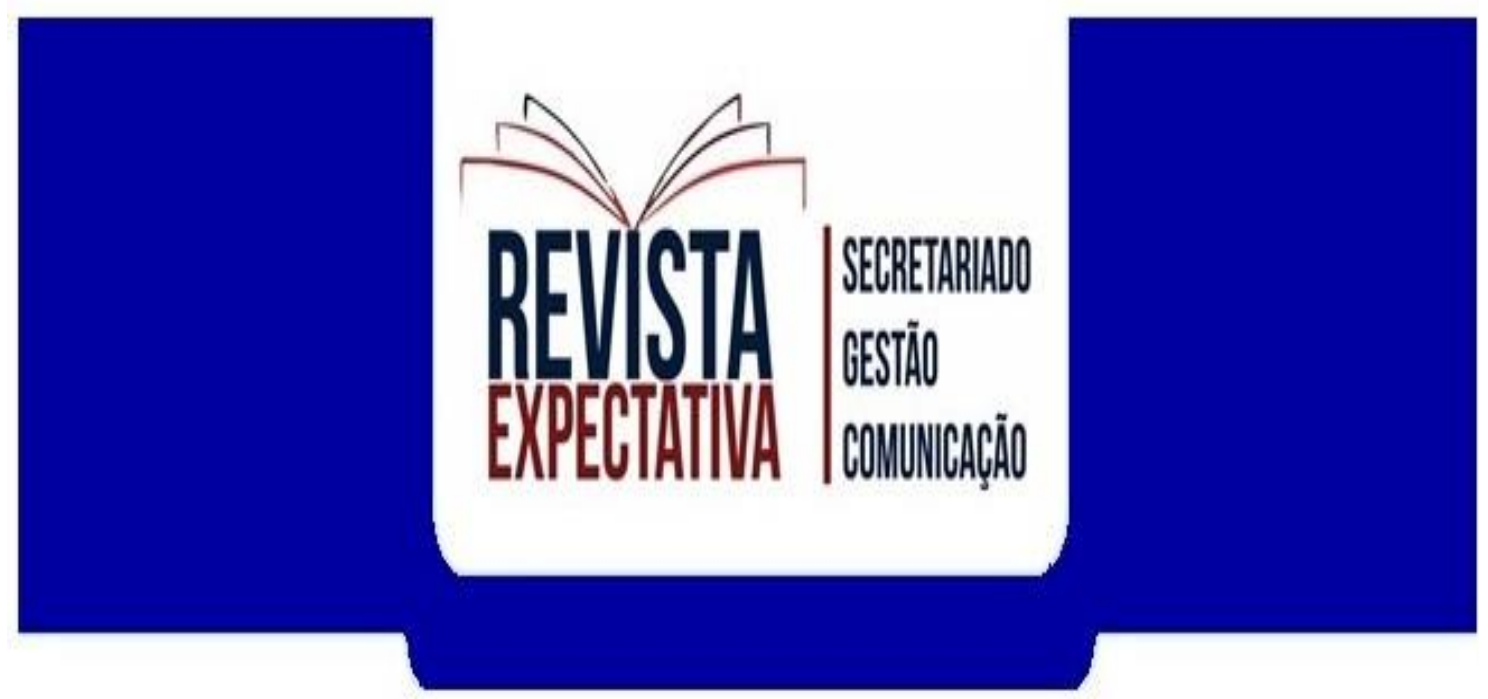

\title{
LÍNGUA ESPANHOLA VOLTADA AOS NEGÓCIOS: DESCRIÇÃO E ANÁLISE DO PERFIL DISCENTE ${ }^{1}$
}

\author{
Keslen Cristina da Silva Dutra², Andréia Roder Carmona Ramires ${ }^{3}$
}

Resumo: Conhecer as expectativas discentes para o conhecimento de uma língua estrangeira é fator relevante para auxiliar o docente no desenvolvimento de suas metodologias e didáticas, tendo em vista que muitas são as necessidades dos alunos ao se interessarem pela aprendizagem de línguas. Seguindo esse tema, concebemos a ideia de que no ensino de línguas para fins específicos, mais especificamente o do âmbito dos negócios, o processo de ensino e aprendizagem de línguas estrangeiras deve fazer com que 0 aprendiz desenvolva, na língua alvo, competências e conhecimentos específicos de suas respectivas áreas de trabalho, ou seja, ampliar as competências comunicativas direcionadas à prática da profissão. Por conseguinte, objetivamos neste artigo, investigar e analisar aspectos que envolvam, e descrevam, o perfil do discente que frequenta um projeto voltado para o ensino de língua espanhola com fins específicos, ofertado pela UNESPAR, Campus Apucarana. Visamos também fazer com que os dados coletados e aqui descritos venham a auxiliar futuros trabalhos em língua estrangeira para fins específicos, com o fito de promover mais debates nessa área de estudo bastante profícua do ensino de línguas.

\footnotetext{
${ }^{1}$ Este trabalho é um recorte de uma pesquisa desenvolvida como Trabalho de Conclusão de Curso de Secretariado Executivo Trilíngue, na Universidade Estadual do Paraná, no ano de 2017.

2 Graduada em Secretariado Executivo Trilíngue (2017) e Pós-Graduanda em Gestão de Negócios e Inovação. Atuação profissional na área Secretarial da empresa UNIMED Apucarana. https://orcid.org/0000-0001-9164-057X

3 Docente adjunta de Língua Espanhola para Fins Específicos - Universidade Estadual do Paraná - UNESPAR. Doutorado concluído em 2015, pela Universidade Estadual de Londrina (programa de Estudos da Linguagem), com estágio de doutoramento na Universidad de Salamanca - Espanha, promovido pela instituição de fomento CAPES - Coordenação de Aperfeiçoamento de Pessoal de Nível Superior. https://orcid.org/0000-0003-1482-6586
}

Editor: Cezar Roberto Versa

Recebido em: 27/03/2020 - Revisado em: 08/04/2020 - Aprovado em: 20/06/2020

Revista Expectativa- e-ISSN 1982-3029 - v.19 - n.1 - jan./jun. - 2020 
Palavras-chave: Língua para Fins Específicos. Perfil. Extensão.

\begin{abstract}
There are many needs concerning the student's interested in learning a foreign language. Knowing their expectations and academic motivations in learning a new language it's an important fact in helping teachers develop their methods and teaching technics. Following the theme, we concebe the idea that in the area of language teaching, specifically in the business field, the teaching and learning process must lead the novice to develop - in the language of study - their own specific knowledge regarding their work field, in other words, to increase their communication skills specifically directed to their practical line of work. That being said, in this article we objective the investigation and analysis of the different aspects regarding the student's profile that are currently in a spanish language project with specific means, brought by UNESPAR, Apucarana City Campus. We also aim to provide the collected data to further studies in foreign languages to specific means, with the intent to bring more discussion and debates in this very profitable area of language teaching.
\end{abstract}

Keywords: Specific mean language. Profile. Extension.

\title{
1 INTRODUÇÃO
}

A globalização tem se configurado, desde o início da década de 1990, como um dos mais importantes processos de união econômica, social, cultural e política, bem como uma via de diminuição de custos com meios de transporte e comunicação de países desenvolvidos e em desenvolvimento. A formação de uma "aldeia global" veio como consequência da ascensão dessa globalização, fato que faz com que os mercados internos busquem, cada vez mais, capital humano especializado, profissionais que apresentem maior facilidade de adaptação a essa forma de trabalho, de interação entre países e, consequentemente, entre culturas.

De acordo com Oliveira (2008), o mundo corporativo exige um novo perfil de profissional, um agente que se adapte a tecnologia disponível para melhor atender os clientes; profissionais que tenham competências para compreender, captar, analisar, refletir criticamente e interpretar a realidade atual. 
Atrelado a todos essas competências, geradas pelo mundo hodierno para corresponder às novas necessidades e exigências da sociedade moderna, os profissionais que apresentem o domínio de uma ou mais Línguas Estrangeiras (LE), se transformam em peça chave e fundamental dentro do mercado de trabalho, configurando um profissional diferenciado dentro das instituições.

Por conseguinte, a aprendizagem da LE, para um melhor desempenho no cenário de trabalho atual e global, é vital, uma vez que o mercado dos negócios está cada vez mais conectado a todas as partes do mundo.

Sánchez-Enterría (2009, p.11) pontua que "a globalização alavancou desde o começo do novo século, uma mudança na oferta e demanda dessas aprendizagens que representou um forte impulso para o estudo das linguagens de especialidade". 4

Desta feita, entendemos que a aprendizagem de línguas no âmbito dos negócios, dentre outras capacidades, deve desenvolver uma competência comunicativa $^{5}$ com objetivo bem traçado e dirigido. Mas de que maneira e para qual público?

A ideia inicial para essa pesquisa surgiu da necessidade de conhecermos os projetos voltados para alunos da área de bacharelado na UNESPAR ${ }^{6}$ - Campus Apucarana, relacionados ao ensino e aprendizagem de LE. E seguindo esse objetivo, nos depararmos com a constatação de que havia, em 2016, apenas um projeto de extensão para o ensino de línguas voltado para alunos de bacharelado. Desta feita, pesquisamos e tentamos conhecer, quais são os alunos que o frequentam, haja vista que entendermos os objetivos e perfil do alunado que aprende uma LE é questão fundamental no processo de desenvolvimento desses estudantes, pois dessa forma é possível obtermos uma compreensão mais efetiva sobre o desenvolvimento

\footnotetext{
4 "la globalización ha ponteciado desde el comienzo del nuevo siglo, un cambio en la oferta y la demanda de estos aprendizajes que ha representado un fuerte impulso para el estudio de los lenguajes de especialidad" (SANCHEZ-ENTERRÍA, 2009, p. 11).

${ }^{5}$ Concebemos o conceito de Compêtencia Comunicativa como sendo "a capacidade de uma pessoa se comportar de maneira eficaz e adequada numa determinada comunidade de fala; isso implica respeitar um conjunto de regras que inclui tanto as da gramática e os outros níveis da descrição linguística (léxico, fonética, semântica) quanto às regras de uso da língua (língua em uso) relacionadas com o contexto sociohistórico e cultural no qual acontece a comunicação" (PERIS, 2008, p. 90).

6 Universidade Estadual do Paraná.
}

Revista Expectativa- e-ISSN 1982-3029 - v.19 - n.1 - jan./jun. - 2020 
da aprendizagem discente e elaborar de forma mais específica o conteúdo a ser ministrado.

Observando a estreita relação entre a aprendizagem de LE e o melhor desenvolvimento de profissionais no âmbito do mercado, entendemos que essa pesquisa se justifica, em razão de que, como afirmamos anteriormente, o mundo está cada vez mais imbricado e, por sua vez, conectado.

Assim, este estudo tem por objetivo (I) investigar e descrever o perfil dos acadêmicos participantes de um projeto de extensão voltado para o ensino de LE da área dos negócios, realizado no ano de 2016; bem como (II) traçar um panorama dos pontos mais significativos verificados com o levantamento dos dados da pesquisa, ocorrida na Universidade Estadual do Paraná (UNESPAR-Apucarana).

Para essa estruturação, este texto apresenta, primeiramente, a literatura especializada na área de ensino de Línguas Estrangeiras Fins Específicos. Apresentamos também, de modo sucinto, questões relacionadas ao projeto de extensão pesquisado. A seguir, exibimos a metodologia da elaboração de nossa investigação e expomos nossas análises a respeito do objeto de pesquisa. Por fim, passamos às considerações finais.

Desta feita, descrevendo uma pequena parcela sobre o alunado de bacharelado, esperamos subsidiar discussões e o desenvolvimento de mais trabalhos e projetos voltados para o ensino de LE relacionados aos discentes dessa área, constatando que esse é um campo fértil para o desenvolvimento de pesquisas que versem sobre essa temática.

\section{REFERENCIAL TEÓRICO}

2.1 LÍNGUA ESTRANGEIRA PARA FINS ESPECÍFICOS E SUAS PECULIARIDADES DE APRENDIZAGEM

É inconteste a relevância da aprendizagem de LE para o profissional da área dos negócios. Conforme Brancher e Santos (2007), é mister que 
aquele que atua na área dos negócios possua domínio de um idioma estrangeiro, posto que deve estar apto a se comunicar e interagir de maneira eficaz também em LE realizando tradução, leitura e interpretação de textos e documentos, dominando também interações da fala, em situações tais como ligações e atendimento a executivos de outros países e, sobretudo, com clientes, de maneira geral, sendo esse um fator crucial para o melhor desenvolvimento em sua profissão.

Dominar uma ou mais LE e conhecer também seus protocolos culturais $^{7}$ se tornou essencial para aqueles profissionais que estão sendo inseridos, almejam ou já trabalham em grandes empresas existentes no Brasil ou até mesmo para os que pretendem seguir carreira em empresas em outros países.

Abadía (2000) pondera que ao aprender uma LE, o falante traz para a sala-de-aula sua própria cultura e um sistema de valores e esse processo de interação deve desenvolver a interculturalidade como capacidade de aceitar a diferença e descobrir uma nova maneira de ver o outro por meio do uso da LE em contextos reais de fala.

Tratando mais especificamente sobre a aprendizagem de Língua Espanhola (doravante LEsp), essa ainda ocupa lugar de destaque no cenário comercial brasileiro e também mundial. A aprendizagem dessa língua ganhou maior visibilidade no Brasil após a assinatura do Tratado de Assunção, feita pelos governos do Brasil, Paraguai, Argentina e Uruguai, e que deu origem ao Mercado Comum do Sul- (MERCOSUL), em março de 1991.

Sedycias (2005, p. 35) afirma que há uma necessidade premente em conhecer mais de uma língua diferente da materna e o conhecimento a respeito da LEsp também é de grande urgência, posto que

com a advento do MERCOSUL, aprender espanhol deixou de ser um luxo intelectual para ser tornar praticamente uma emergência. Além do MERCOSUL, que já é uma realidade, temos ao longo de nossa fronteira um enorme mercado, tanto do ponto de vista comercial como cultural. Porém, esse mercado não fala nosso idioma. Com a exceção de três pequenos enclaves não hispânicos no extremo norte do continente (a Guiana, o Suriname e a Guiana Francesa) todos os países desse mercado falam espanhol. Mas, além da América do Sul,

\footnotetext{
${ }^{7}$ Nesse trabalho, não abordaremos os aspectos referentes ao conhecimento cultural advindo do desenvolvimento da aprendizagem de línguas estrangeiras. Optamos por não caminharmos também por essa vereda de pesquisa devido a esse não ser nosso foco de estudo.
} 
temos a América Central e o México onde também predomina o idioma espanhol.

Como veículo de comunicação, a LEsp está em 2ํ. lugar como língua mais falada em âmbitos comerciais.

De acordo com dados oriundos do Instituto Cervantes (2016), a relevância da aprendizagem da LEsp é destacável, pois:

$\checkmark$ É falada como língua oficial em 21 países (Argentina, Bolívia, Chile, Costa Rica, Colômbia, Cuba, El Salvador, Equador, Espanha, Guatemala, Guiné Equatorial, Honduras, México, Nicarágua, Panamá, Paraguai, Peru, Porto Rico, República Dominicana, Uruguai, Venezuela);

$\checkmark \quad$ É segunda língua materna mais falada no mundo;

$\checkmark \quad$ É segundo idioma de comunicação internacional;

$\checkmark$ Os Estados Unidos contam com uma comunidade hispana representativa e atuante;

$\checkmark \quad$ Mais de 21 milhões de alunos estudam a LEsp como LE.

Refletindo nesse panorama de crescimento do aprendizado da LEsp, observamos também que o estudo dessa língua nas universidades do Brasil está progressivamente se expandindo. Segundo Stefanello (2007, p. 54):

\begin{abstract}
uma pessoa que adquiriu uma LE como segunda língua sabe mais do que compreender, falar, ler e escrever frases ou palavras. Ela reconhece também as maneiras como palavras e estruturas da língua são utilizadas para conseguir um efeito comunicativo. A aprendizagem de uma LE abrange a aquisição da capacidade de compor frases corretas que depende da manifestação do conhecimento do sistema linguístico da língua que está sendo aprendida. Porém, além do emprego de formas gramaticais, essa aprendizagem também deve incluir a aquisição da compreensão de como essas frases são apropriadas para o uso num contexto situacional o mais real possível.
\end{abstract}

Dessa maneira, as universidades que ofertam cursos de bacharelado em Secretariado Executivo, Turismo, Direito, Administração e Comércio Exterior, deverão preparar seus alunos para estarem atentos às frequentes mudanças tecnológicas e sociais desse mundo globalizado e não somente buscar formar profissionais com competências técnicas.

Mas para que o aluno, futuro profissional, consiga se comunicar e 
desenvolver essa aprendizagem em LEsp, voltada para aspectos reais da língua, há de se pensar no método que se deve ensinar para obter o resultado esperado o mais prontamente possível.

Pensando nos motivos, nos objetivos bem delimitados e no público que irá aprender uma LE foi que nasceu o ensino de línguas para fins específicos, (doravante ELFE).

Segundo as proposições de Clercq, Lioce e Swiggers (2000, p. 12),

desde a Idade Média, vê-se aparecer estes manuais de conversação, que se apresentavam sob forma de diálogos-modelo que deveriam permitir ao usuário aprender rapidamente a língua falada no dia-a-dia. Trata-se então de instrumentos didáticos centrados quase exclusivamente sobre a competência, mais frequentemente a competência oral.

Também durante a $2^{\underline{a}}$ guerra mundial, já existia essa imprescindibilidade de aprendizagem rápida e direcionada de LE. Em decorrência das transformações advindas das atividades científica, militar e econômica daquela década (CONDE-FERNÁNDEZ, 2005), surge essa metodologia de ensino, que pretende ampliar as competências comunicativas voltadas à prática de profissionais, trabalhando mais especificamente aspectos do vocabulário potencial e instrumental.

O primeiro idioma a ser ensinado no ELFE foi a língua inglesa. Segundo Beltrán (2005, p. 1112),

\begin{abstract}
si tomamos como referência a experiência da língua inglesa, vemos que o desenvolvimento desta tendência parte da constatação de que o enfoque tradicional do ensino de idioma na descrição de regras gramaticais e tradução, não capacita para se desenvolver eficazmente em situações reais de comunicação (BELTRÁN, 2005, p. 1112). ${ }^{8}$
\end{abstract}

Sendo assim, em 1960, o chamado ELFE ganhou força no mundo do ensino e se consolidou nessa esfera, porém esse método só chegou ao Brasil em 1970, em decorrência da carência dos alunos das universidades brasileiras

\footnotetext{
8 "si tomamos como referencia la experiencia de la lengua inglesa, vemos que el desarrollo de esta tendencia parte de la constatación de que el enfoque tradicional de la enseñanza de idioma en la descripción de reglas gramaticales y traducción, no capacita para desenvolverse eficazmente en situaciones reales de comunicación" (BELTRÁN, 2005, p. 1112).
} 
no âmbito da leitura de conteúdos de áreas específicas. Com o passar do tempo, o ensino foi se transformando.

Para Robinson (1991), o ELFE pode ser dividido em fins acadêmicos (geral ou específica para uma disciplina) ou profissionais (negócios, social e tecnologia) e deve oferecer autonomia aos alunos transmitindo conhecimentos de línguas (materna ou estrangeira), instruindo os estudantes a se posicionarem em situações acadêmicas e/ou profissionais específicas com ação e criatividade, aprimorando sua comunicação em situações reais de fala, em LE.

Desse modo, essa metodologia de ensino tem o intuito de instruir o aluno a ter eficiência na comunicação na LE de forma direcionada a suas necessidades, buscando desenvolver competências para uma comunicação eficaz, nesse caso, no âmbito do trabalho. De acordo com Rodríguez (2004, p. 7), "num curso de línguas para fins específicos, o que se pretende é potencializar no aluno o desenvolvimento de uma competência limitada para que seja capaz de movimentar-se em contextos bem determinados".

Em vista disto, a Língua Estrangeira voltada para Fins Específicos proporciona ao indivíduo aprender uma língua diferente da materna e simultaneamente o vocabulário necessário e direcionado para sua área de atuação profissional.

Devido a todos esses apontamentos, constatamos que entrevistas com discentes de um curso de extensão voltado para o ensino de LEsp da área dos negócios, torna-se revelador de muitos aspectos presentes no âmbito acadêmico da UNESPAR, sobretudo ao campo do desenvolvimento de projetos voltados para a área do bacharelado.

\subsection{PROJETO DE EXTENSÃO - LABORATÓRIO DE LÍNGUAS:} DESENVOLVENDO A APRENDIZAGEM DO ESPANHOL DOS NEGÓCIOS

Para situar melhor o leitor no assunto abordado, explanamos rapidamente algumas considerações a respeito do projeto que nos serviu de base de coleta de dados para a elaboração desta pesquisa.

O projeto anteriormente mencionado, iniciou-se no ano 2000 com uma 
professora de LEsp, já aposentada. Entretanto, naquele ano, o projeto tinha um objetivo diferente do verificado atualmente, em razão de ser voltado para o ensino de nível básico de LEsp aos acadêmicos. O material didático utilizado era o livro Primer Plano 1, da editora espanhola Edelsa e eram ofertadas 20 vagas para cursos da então FECEA - Faculdade Estadual de Ciências Econômicas de Apucarana ${ }^{9}$ - e também para funcionários, bem como para a comunidade externa.

Já em 2016, o curso se intitulava Laboratório de Línguas: Desenvolvendo a aprendizagem do Espanhol dos Negócios e apresentava como objetivo o ensino da LEsp voltada para a área dos negócios, ou seja, tem um perfil delimitado para os cursos de bacharelado da UNESPAR - Campus Apucarana. Funcionou desde 2010 até 2018 e foi coordenado por outra docente da área do ensino de LEsp da instituição, mantendo a oferta de 20 vagas para acadêmicos da UNESPAR, bem como funcionários e comunidade externa. O material didático utilizado estava composto por um compêndio de vários textos da área dos negócios e também algumas atividades advindas de 2 livros da área de especialidade do ensino de língua espanhola, a saber: Técnicas de Correo Comercial e Técnicas de Conversación Telefónica, ambos da editora Edelsa.

Porém, observamos que, mesmo sendo esse projeto voltado para 0 ELFE, ou seja, nesse caso voltado para acadêmicos das áreas de bacharelado, havia a presença também, ainda que em menor número, de discentes de outra área de conhecimento, como da licenciatura, visto que observamos a presença no projeto de acadêmicos do curso de letras - espanhol e também matemática.

Assim, ousamos afirmar que esse curso era relevante no âmbito acadêmico desse Campus, posto que alcançou não somente o público alvo a que foi destinado, mas também discentes de outras áreas de conhecimento e também a comunidade externa.

\section{PERCURSO METODOLÓGICO}

A metodologia utilizada para a realização deste trabalho está

\footnotetext{
9 A FECEA tornou-se parte da Universidade Estadual do Paraná no ano de 2013, quando essa foi institucionalmente autorizada em 5 de dezembro de 2013, pelo Decreto de número 9.538.
}

Revista Expectativa- e-ISSN 1982-3029 - v.19-n.1 - jan./jun. - 2020 
fundamentada em pesquisas bibliográficas que descrevem, de forma breve, questões relacionadas ao ensino ELFE e a relevância da aprendizagem de LE para o profissional da área dos negócios.

Para o levantamento dos dados analisadas e debatidos nessa pesquisa, utilizamos as respostas advindas de um questionário, composto por questões objetivas, aplicado ${ }^{10}$ a discentes participantes do referido projeto, em abril de 2016.

Esse questionário contava com três partes as quais descrevemos a seguir: (i) na primeira parte extraímos dados relacionados ao perfil dos informantes. Logo em seguida, (ii) na segunda parte, a pergunta pesquisavam quais eram os interesses, e motivos, dos participantes se interessavam em estudar a LEsp; (iii) na terceira e última parte do questionário, buscamos verificar quais as competências, e quais atividades dentro de cada competência, mais se destacavam no interesse de aprendizagem dos acadêmicos, a saber: compreender, falar, ler e escrever.

Não obstante, neste trabalho, vamos nos ater a descrição apenas da primeira parte de nosso questionário, ou seja, abordamos os aspectos referentes ao estabelecimento do perfil dos alunos que estudaram LE nesse curso de extensão. Portanto, apresentamos aqui dados referentes a seis (6) categorias, a saber: a) gênero; b) faixa etária; c) origem; d) curso oriundo; e) ofício; f) tempo dedicado ao estudo de línguas.

Por conseguinte, caracterizamos nossa pesquisa como um estudo de caso ao entendermos ser essa direcionada para um contexto específico bem delimitado, ou seja, um curso voltado para o ensino de LEsp para fins específicos, mais precisamente a área dos negócios. Nas considerações de Cohen; Manion; Morrison (2001 apud CALVO, 2011),

estudos de caso empenham-se em retratar o que parece ser em uma situação particular para captar a realidade e a descrição das experiências vividas pelos participantes, seus pensamentos e sentimentos relacionados a uma situação.

Desse modo, queremos ressaltar que não estamos generalizando os resultados aqui coletados e apresentados. Estamos descrevendo apenas uma pequena amostragem que se refere somente a um ano do curso aqui

${ }^{10} \mathrm{O}$ referido questionário é apresentado no Apêndice 1 deste artigo.

Revista Expectativa- e-ISSN 1982-3029 - v.19 - n.1 - jan./jun. - 2020 
pesquisado. Outras pesquisas, com outros sujeitos informantes, em outro momento histórico, poderão apresentar outros dados e, por conseguinte, outras conclusões.

Com relação à análise de nossos dados, optamos pela pesquisa interpretativista, em razão de que esta modalidade, segundo Schwandt (2006, p. 198),

\begin{abstract}
considera a compreensão um processo intelectual pelo qual um conhecedor (o investigador na função de sujeito) adquire conhecimento a respeito de um objeto (o significado da ação humana). [...]. Assim, nas tradições interpretativas, o intérprete objetiva (isto é, supervisiona e contesta) o que deve ser interpretado.
\end{abstract}

A fim de preservar o nome dos participantes desta pesquisa, adotamos as letras de $A$ até $T$ para referência aos dados oriundos dos 20 acadêmicos e, assim, apresentarmos suas respostas com melhor clareza e objetividade.

\title{
3.1DURAÇÃO DAS ENTREVISTAS
}

Foi realizado um encontro geral com os discentes, 20 no total, com duração de aproximadamente 30 minutos na Instituição de Ensino Superior Unespar - Campus Apucarana. Nesse encontro, ademais das questões referentes à pesquisa, foi-lhes entregue uma folha apresentando um Termo de Consentimento Livre e Esclarecido, para que os dados desta pesquisa fossem utilizados legalmente.

\section{PESQUISA: DESCRIÇÃO E ANÁLISE}

\subsection{PERFIL DOS SUJEITOS PESQUISADOS}

Como apresentado na metodologia, o levantamento de dados para a constituição deste trabalho foi realizado no mês de abril do ano de 2016, ou seja, no início das aulas do projeto e respondido por todos os acadêmicos que o frequentavam.

A partir das respostas advindas do questionário, elaboramos o perfil dos alunos do curso voltado para o ensino de língua espanhola para os negócios. 


\subsubsection{Categorias:}

a) Gênero:

Iniciando nossa descrição, verificamos que dos vinte participantes, quinze são mulheres, quatro são homens e um informante não respondeu a essa questão.

Ao realizarmos nossa pesquisa bibliográfica, observamos que várias profissões eram exercidas por homens que obtinham prestígio para com essas atividades (NEVES, 2008). Com o passar dos séculos, e a necessidade de utilização de mão de obra feminina devida, sobretudo, às grandes guerras que dizimaram parte considerável da população mundial de homens, as mulheres ocuparam os espaços antes predominantemente masculinos e começaram a se destacar também no âmbito profissional. Todavia, não apenas pela necessidade de mão de obra feminina, mas também por outros vários fatores, podemos constatar nas últimas décadas que a presença da mulher na sociedade está cada vez mais estabelecida.

Os dados do Censo da Educação Superior (INEP, 2013) indicam que a quantidade de matrículas realizadas em cursos de graduação chega a sete milhões, e desse total, 57\% são mulheres. Segundo Caetano e Neves (2009, p. 159) "a partir dos anos 90 , a taxa de escolaridade feminina também aumentou em relação à masculina e alcançou níveis elevados". Constatamos também que nas últimas três décadas, a participação feminina no mercado de trabalho apresenta aumento impulsionado talvez pela expansão de oportunidades econômicas potenciando o desenvolvimento das atividades laborais desse gênero (Banco Mundial, 2011).

Dessa forma, nossos dados corroboram as estatísticas quando constatamos que a maioria dos estudantes que frequentam o referido curso de LE na UNESPAR é do gênero feminino.

b) Faixa Etária

Referindo-nos à segunda categoria de nosso estudo, idade dos 
acadêmicos, os respondentes se classificam entre dezenove (19) a vinte e cinco (25) anos, sendo que dois deles têm dezenove anos, quatro tem vinte anos, quatro tem vinte e um, dois participantes tem vinte e dois anos e apenas um tem vinte e três anos, três tem vinte e quatro anos, três afirmam ter vinte e cinco anos. Apresentamos uma tabela para que essas informações sejam melhor observadas e entendidas:

Tabela 1

\begin{tabular}{|r|c|}
\hline IDADE & DISCENTES \\
\hline 19 & 2 \\
\hline 20 & 4 \\
\hline 21 & 4 \\
\hline 22 & 2 \\
\hline 23 & 1 \\
\hline 24 & 3 \\
\hline 25 & 3 \\
\hline 42 & 1 \\
\hline
\end{tabular}

Fonte: Autoras

Verificamos também que somente um dos informantes afirma ter quarenta e dois (42) anos, fato que nos faz entender que o perfil dos discentes pesquisados é, em sua maioria, constituído por acadêmicos jovens.

De acordo com a Associação Nacional dos Dirigentes das Instituições Federais de Ensino Superior no Brasil (ANDIFES, 2011, p. 42), "o estudante das federais é jovem. O maior grupo, quase 14\%, tem 21 anos de idade. A grande maioria $(73,7 \%)$ está na faixa de 18 a 24 anos $(74,5 \%$ na faixa de até 24 anos). Ressalte-se que a média de idade mantém-se em 23 anos".

Dessa forma, apesar desses dados se referirem a uma instituição federal, entendemos que eles apresentam certa uniformidade com nossa instituição, que é do âmbito estadual.

Queremos destacar que, com esse dado verificamos que o perfil etário do acadêmico desse Campus mudou nos últimos anos. Antes da criação da 
UNESPAR, os discentes dos cursos da então FECEA eram predominantemente adultos, com média de idade de 30 anos, que aliavam trabalho ao estudo. A partir dessas considerações, entendemos que esse panorama se alterou, a julgar por haver uma maioria significativa de jovens presentes nos dados de nossa pesquisa.

\section{c) Origem}

$\mathrm{Na}$ expectativa de elaborar um mapeamento das localidades dos participantes da pesquisa, descrevendo nossa terceira categoria, origem dos informantes, observamos que os respondentes são oriundos de diversas cidades do estado do Paraná, sendo 12 de Apucarana, dois de Cambira, um participante de Missal e três advindos de Arapongas.

Entretanto, ao nos depararmos com nossos dados, observamos que não apenas do estado da nossa universidade advém os sujeitos pesquisados, posto que há acadêmicos advindos também de outros estados brasileiros, tais como São Paulo (São José dos Campos) e Minas Gerais (José Monlevade). Como observamos, os acadêmicos participantes desse projeto advém de cursos de graduação da universidade e desse modo, entendemos que a UNESPAR já apresenta destaque no patamar educacional, em âmbito nacional, considerando que não apenas do estado do Paraná há estudantes nesse Campus. Esse fato demonstra que cursos na área de línguas voltados para a área de bacharelado, são necessários para atender a demanda de acadêmicos que, em grande maioria nesse Campus, são da área dos negócios e advindos de todo o Brasil.

Ao realizarmos nossa pesquisa para sabermos quais projetos de extensão eram ofertados para a área dos negócios em nosso Campus, constatamos que, em 2016, apenas esse projeto que hoje estudamos e descrevemos aqui estava voltado para a área do bacharelado. Esse fato nos faz também refletir sobre a necessidade dos acadêmicos cumprirem suas horas complementares de atividades ${ }^{11}$.

\footnotetext{
${ }^{11}$ Considera-se, segundo a Matriz curricular do curso de Secretariado Executivo Trilíngue da UNESPAR Apucarana, o cumprimento de 120 horas de Atividades Complementares (AT) necessárias para a obtenção do título de bacharel no referido curso. Esse é o curso com menor exigência de horas para o 
Verificamos que mesmo com o esforço de alguns cursos do Campus em sanar essa lacuna, muitas graduações não oferecem aos acadêmicos nem $40 \%$ do número de eventos para que o estudante atinja as horas complementares necessárias para concluir a graduação, fato que faz com que os discentes tenham que participar, dentro da universidade, muitas vezes, de outros cursos que pouco contribuem com a área de suas formações. Consideramos ser esse um fator negativo para o desenvolvimento do processo de aprendizagem discente e o futuro profissional no mercado de trabalho.

d) Graduação (curso oriundo)

Analisando nossa próxima categoria, deparamo-nos com os cursos de graduação dos quais os acadêmicos são oriundos. Os participantes do projeto são estudantes de vários cursos da UNESPAR, sendo 7 acadêmicos de Administração, 5 acadêmicos do curso de Secretariado Executivo Trilíngue, 3 acadêmicos de Ciências Contábeis, 2 acadêmicos de Economia, um acadêmico de Serviço Social, um de Letras - Espanhol e outro estudante do curso de Matemática, a área de ciências exatas.

Ao nos depararmos com esses dados, constatamos que, apesar deste curso de LE ser voltado para a aprendizagem de línguas da área dos negócios, ele foi considerado relevante também por discentes da área de licenciatura.

Essa constatação ratifica nossa proposição anterior de que cursos na área de línguas devem ser ofertados com maior frequência nesse Campus, tendo em vista que encontramos demanda (interesse) advinda de diferentes áreas de conhecimento, de diferentes cursos.

O fato de encontrarmos estudantes dos cursos de letras (espanhol) e até mesmo acadêmicos da área de ciências exatas, como do curso de matemática, nos faz pensar que uma pesquisa que verse a respeito de aspectos relacionados ao perfil discente de LE para fins específicos dará, seguramente, características de como podemos trabalhar de maneira mais efetiva para 0 alcance de um melhor desenvolvimento do processo de aprendizagem acadêmico, subsidiando futuras aprendizagens, posto que 
entendemos que a aprendizagem se dá de maneira individual e por isso, decorre de diferentes tipos de vivencias acumuladas pelo aluno ao longo de sua vida.

Como outrora afirmamos, ao conhecermos o perfil discente dos participantes desse projeto de extensão, será possível elaborarmos com maior objetividade o curso a ser ofertado a esses alunos, repensando os materiais a serem utilizados e a metodologia a ser adotada para um alcance mais efetivo dos objetivos específicos de aprendizagem, por isso sendo necessário pesquisar os perfis discentes em bacharelado.

e) Ofício

Na categoria de pesquisa sobre qual era a ocupação do acadêmico (se trabalha e/ou estuda) os dados nos apontam que, dos 20 informantes, 15 trabalham e estudam, 4 somente estudam; e um (1) participante deixou essa resposta em branco.

Verificando que a maioria dos informantes trabalha e estuda, o fato de se dedicarem ao estudo a LEsp fora do ambiente de sala de aula de suas graduações é considerado por nós como um ponto positivo para seus desenvolvimentos acadêmicos e, sobretudo, profissional.

Não pesquisamos a respeito de aspectos financeiros de nossos sujeitos informantes. Entretanto, entendemos que para alunos que trabalham e estudam, pagar um curso de LE de modo particular pode onerar suas despesas e ser um fator desmotivador. Outro fator que, em nosso entendimento, pode desestimular o processo de aprendizagem dos alunos é o de terem pouco tempo para a dedicação e participação em cursos de LE, posto que trabalham o dia todo e frequentam no período noturno suas graduações.

Não obstante, a oferta pela UNESPAR - Apucarana, de um curso voltado para a área de bacharelado se mostra destacável, posto que verificamos que há a necessidade, a demanda, por parte dos estudantes, não obstante, essa lacuna está presente ainda a julgar pela pouca oferta de vagas nesse curso de línguas (apenas 20) e o grande volume de acadêmicos que se apresentaram interessados e se inscreveram no referido curso de extensão. 
Ao ofertar mais espaços para que 0 acadêmico tenha contato com o desenvolvimento da aprendizagem da LE desejada, bem como possa preencher suas horas complementares, a UNESPAR estará realizando a ponte entre ensino e efetiva contribuição com a comunidade acadêmica (interna e externa), um dos eixos de trabalho que deve oportunizar uma universidade pública à comunidade.

f) Tempo dedicado ao estudo de línguas

Com relação ao tempo semanal dedicado ao estudo de LE, fora do âmbito universitário, os dados são bastante variados. De acordo com as respostas, cinco participantes dedicam uma (1) hora por semana de estudo a LEsp, três responderam que estudam duas (2) horas semanais, outros dois responderam que estudam três (3) horas na semana, dois acadêmicos informaram que estudam de duas a três horas por semana, cinco responderam que estudam quatro horas semanais, dois disseram que estudam 3 vezes por semana e apenas um afirma que não dedica tempo nenhum para estudos em LE fora do âmbito universitário.

Apesar de observarmos diferentes tempos de dedicação aos estudos em língua, em média de uma a quatro horas semanais, de maneira geral, constatamos que os respondentes dedicam sim parte de seus estudos a LEsp fora do âmbito universitário.

Essa ocorrência nos informa que os acadêmicos que frequentam o curso de línguas o fazem, pois já possuem interesse no assunto e buscam obter mais conhecimento sobre um ramo que, para muitos estudantes da área de bacharelado, é um diferencial no mercado de trabalho, o domínio de uma LE. Observando essa dedicação discente ao estudo de LE, ratificamos uma vez mais a relevância desse curso de ELFE dentro do Campus Apucarana como mais um espaço de desenvolvimento de nossos alunos, no que tange a participação em atividades complementares a suas graduações.

\section{CONSIDERAÇÕES FINAIS}

Nesta investigação, coletamos dados para elaborar um panorama a 
respeito do perfil de discentes participantes de um projeto voltado para o ELFE, mais precisamente da área dos negócios na UNESPAR - Campus Apucarana. Assim, nosso corpus de estudo está formado pelas respostas desses discentes, 20 no total, predominantemente avindos da área de bacharelado da UNESPAR.

Destarte, apresentamos algumas considerações gerais de nossa pesquisa:

a) Há em nossos dados o predomínio do gênero feminino no curso analisado;

b) Assim como o registro da idade média do público das universidades federais, os informantes dessa pesquisa igualmente possuem média de 23 anos;

c) Observamos, a partir dos resultados observados, que a origem geográfica dos acadêmicos que participaram da pesquisa, no Campus da UNESPAR-Apucarana, não é formada apenas por paranaenses, considerando que recebemos estudantes de outros estados como São Paulo e Minas Gerais. Desse modo, ousamos afirmar que o interesse por estudar em um curso de nível superior na UNESPAR se estende também para outros estados do território nacional, conforme página 16.

d) O projeto pesquisado foi pensado para ser voltado para o público da área de bacharelado, todavia esse projeto chamou a atenção também de acadêmicos de variados cursos da UNESPAR e não apenas de alunos advindos de cursos que possuem relação com a LEsp, como Secretariado Executivo Trilíngue. Fazemos essa afirmação, pois foi constatada a presença de alunos de licenciatura como os cursos de Letras-Espanhol e também de matemática. Desse modo, confirmamos a importância do domínio de uma LE por meio da grande procura pelo curso de extensão, advinda por parte de acadêmicos de diversas áreas do conhecimento, não somente da área do bacharelado.

e) Fomentando a ideia de que é importante o aprendizado da LE, e levando em consideração o fato de que a maioria dos respondentes da pesquisa trabalha e estuda, (este é um panorama quase unânime nesse 
Campus da UNESPAR) é extremamente válida a iniciativa dos acadêmicos de estudarem em um projeto voltado para línguas. Observamos que, embora a maioria dos informantes da pesquisa conciliam o trabalho ao estudo, ainda assim encontram tempo para fazerem um curso extracurricular;

f) Observamos também que a maioria dos pesquisados se dedica entre uma a quatro horas semanais fora do âmbito universitário. Consideramos esse dado também como um ponto positivo, pois nos mostra que os alunos têm motivação para estudarem LE fora do âmbito acadêmico e esse, a motivação, é um ponto propulsor para o sucesso no processo de aprendizagem de uma língua.

Queremos ressaltar que as questões aqui levantadas podem ser utilizadas futuramente para pesquisas, verificando o grau de interesse e aprendizagem dos discentes em outros momentos de seus processos de aprendizagens.

Finalmente, esperamos que este trabalho auxilie os discentes da área de bacharelado a desenvolverem mais pesquisas nessa área de aprendizagem de línguas e essas possam auxiliam ainda mais sua competência em LE, sabendo que este conhecimento tornou-se essencial para suas carreiras, como já relatado anteriormente.

Desejamos também que outros docentes de ELFE realizam mais trabalhos voltados a essa temática de ensino, haja vista que esse é um espaço profícuo de estudos e elaboração de discussões e pesquisas, no Brasil.

\section{REFERÊNCIAS}

ABADÍA, Pilar Medeiro. Métodos y enfoques en la enseñanza/aprendizaje del español como lengua extranjera. Madrid: Edelsa, 2000.

ANDIFES, 2011, p. 42 Associação Nacional dos Dirigentes das Instituições Federais de Ensino Superior no Brasil. Disponível em: <http://www.andifes.org.br/wpcontent/files flutter/1377182836Relatorio do perfi dos estudantes nas unive rsida des federais.pdf>Acesso em: 23/10/2017

Banco Mundial, 2011. Disponível em:http://siteresources.worldbank.org/EXTANNREP2011/Resources/8070616- 
1315497380273/WBAR11 YearlnReview Portuguese.pdf > Acesso em: $23 / 10 / 2017$

BELTRÁN, Blanca Aguirre. La enseñanza del español con fines profesionales. IN: SÁNCHEZ LOBATO, J; SANTOS GARGALHO, I. (2005). Vademécum para la formación de profesores - Enseñar español como segunda lengua (L2)/ lengua extranjera (LE).Madri: SGEL.

BRANCHER, Naiana. SANTOS, Maria Elizabete Mariano. O domínio das Línguas Estrangeiras e o Profissional de Secretariado Executivo Bilingue. Secretariado Executivo em Revist@, v. 3, 2007. Disponível em <http://www.upf.br/seer/index.php/ser/article/view/1757/1166>. Acesso em: 18/08/2017.

CAETANO, E.; NEVES, C.E. 2009. Relações de gênero e precarização do trabalho docente. Revista HISTEDBR Online, (n. especial):251-263. Disponível em:http://www.histedbr.fae.unicamp.br/revista/edicoes/33e/art16 33esp.pdf. Acesso em: 20/10/2017

CALVO, L. C. S. A identidade profissional de professores e professores de inglês: representações construídas por acadêmicos do terceiro ano do ensino médio. In: REIS, S.; VAN VEEN, K,; GIMENEZ, T. (Org.). Identidades de professores de línguas. Londrina: Eduel, 2011.

CLERCQ, J.; LIOCE, N.; SWIGGERS, P. Grammaire et enseignement du français, 1500-1700. Leuven: Peeters, 2000. Disponível em :http://www.helb.org.br/index.php/revista-helb/ano-8-no-8-12014/227-oensino-de- linguas-para-fins-especificos-elfe-no-brasil-e-no-mundo-ontem-ehoje . Acesso em 17/08/2017.

CONDE-FERNÁNDEZ; M. R.; La enseñanza de la cultura en la clase de español de los negocios. Arco Libros, S. L. 2005. P. 39-74.

Instituto Cervantes - informativo El español: una lengua viva (2016): Disponível em:http://www.cervantes.es/imagenes/File/prensa/El\%20espaol\%20una\%20len gua\%20v iva.pdf Acesso em: 10 de outubro de 2017.

NEVES, Maria da Conceição de Oliveira. Introdução ao Secretariado Executivo. São Paulo: Editorama, 2008.

OLIVEIRA, M. B. (2008). Os profissionais do novo milênio. Petrópolis: 
Vozes.

PERIS, E. M. Diccionario de términos clave de ELE. Madrid: SGEL, 2008.

ROBINSON, P. ESP Today: a practtioner's guide. HemelHamspsted: Prentice Hall International, 1991. Disponível

em :http://www.helb.org.br/index.php/revista-helb/ano- 8-no-8-12014/227-oensino-de-linguas-para-fins-especificos-elfe-no-brasil-e-no- mundo-ontem-ehoje . Acesso em 21/08/2017.

RODRÍGUEZ, M. Fernández-Conde. La enseñanza de la comunicación no verbal en un curso del Español de los Negocios según la ELMT. Memoria de Máster. Universidad Antonio de Nebrija. Hanoi, 2004. Disponível em: http://www.mecd.gob.es/redele/Biblioteca-Virtual/2004/memoriaMaster/2Semestre/FERNANDEZ-CONDE.html Acesso em: 19 de outubro de 2017.

SÁNCHEZ-ENTERRÍA, J. G. EI Español Lengua de Especialidad: Enseñanza y Aprendizaje. Madrid: Arco Libros, 2009.

SEDYCIAS, J. Porque os brasileiros devem aprender espanhol. In: SEDYCIAS, J.(org) 0 ensino de espanhol no brasil: passado, presente, futuro. São Paulo: Editoria, 2005.

SCHWANDT, T. A. Três posturas epistemológicas para a investigação qualitativa: interpretativismo, hermenêutica e construcionismo social. In: DENZIN, N. K; LINCOLN, Y. S. (Eds.). Planejamento da Pesquisa Qualitativa. Porto Alegre: Artmed, 2006.

STEFANELLO, Carla Marli Adiers. Da competência comunicativa à linguístico- discursiva: implicações para o ensino e aprendizagem de língua estrangeira. Dissertação (Mestrado em Letras) -Universidade de Passo Fundo, 2007. 


\section{Apêndice 1}

\section{UNIVERSIDADE ESTADUAL DO PARANÁ}

\section{CAMPUS APUCARANA}

1. Complete el cuestionario sobre sus datos y objetivos de aprendizaje en lengua española:
a) Edad:
b) Sexo:
c) Ciudad/Provincia:
d) Carrera:
e) Institución:
f) ¿Trabaja o Estudia?:
g) Tiempo semanal dedicado al estudio (actividades) de la lengua:

2. ¿Por qué estudia español?:
a) ( ) Es una asignatura obligatoria de mi carrera
b) ( ) Necesito utilizarla como lengua de trabajo
c) ( ) Voy a trabajar en un país hispanohablante
d) ( ) Necesito leer textos en español
e) ( ) Me gusta aprender idiomas
f) ( ) Quiero vivir en un país de habla española
g) ( ) Quiero trabajar como traductor (a)
h) ( ) Me interesa la lengua y la cultura 
